Milton Rossel

\title{
Del registro de mis lecturas
}

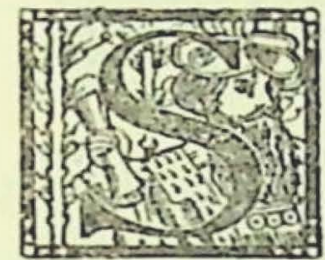

[ AVENTAMOS la bruma que envuelve el camino recorrido en nuestra vida, seres y hechos se confunden en el tumulto de los recuerdos. Algunos surgen nítidos en la conciencia, ensombrecidos inexorablemente aquellos que no se proyectan en una vigencia de acción o de enseñanza. De ahí que la historia sólo reanima a hombres y aconteceres que marcaron hitos en el decurso de la humanidad o de los pueblos. Filósofos, sabios, santos, escritores, poetas, artistas, políticos, guerreros, sobreviven en el alma social por la emoción admirativa que en las generaciones provoca el mensaje de saber, de bondad, de sacrificio, de belleza, de heroísmo que ellos legaron a la posteridad. En el individuo la resonancia de ese mensaje se restringe al particular interés o simpatía que suscitan quienes de alguna manera influyen en nuestros pensamientos, sensibilidad o conducta. Tal es el caso de ciertos profesores. Si recordamos el nombre de todos los que tuvimos en el liceo o en la Universidad, con su imagen física y peculiaridades distintivas, son pocos los que nos incitan a la gratitud.

La misión del profesor se hace más eficaz y perdurable por el poder generador de la siembra antes que por la sapiencia y número de conocimientos transmitidos. Excepcionales son los profesores en que se confunden dádiva de sembrador y saber hondo y clarificado, en esa unidad ideal del maestro auténtico. 
Don Enrique Molina es de éstos. Por eso la huella que dejó en nosotros ha permanecido intacta en nuestra existencia. Fuimos su alumno en la clase de Historia en el viejo Liceo de Concepción (1916), adonde venía de rector después de haberlo sido del Liceo de Talca. Vivíamos en el hervor de la adolescencia, con esos quince años de bulliciosa rebeldía de esa etapa de la vida. Don Enrique tenía ya el prestigio del maestro que sabe comprender las contradicciones y angustias de la juventud. Se captó de inmediato la simpatía de los liceanos. Su figura esbelta, ágil, juvenil y sus actitudes bondadosas nos impresionaron. Hubo dos detalles que bastaron para ganarse a los muchachos: los llamaba por el nombre de pila, conservado en su memoria, y los saludaba en la calle sacándose el sombrero como a personas mayores. Sus clases eran amenas, de gran claridad y orden en la exposición de las materias, ilustrando los hechos históricos con referencias a circunstancias del momento. Antes que ceñirse al texto, prefería él formar la personalidad del joven, al cual interrogaba frecuentemente, estimulándolo a la reflexión y al pensar propio. Introdujo una modalidad muy rara entonces y ahora en los profesores: poner la nota máxima al alumno que contestara bien, sin ese regateo del que cree que la calificación óptima no debe darse. Examinaba tratando de que el muchacho respondiera satisfactoriamente, llevándolo al campo de lo que parecía conocer. No le interesaba determinar lo que el alumno no sabía, sino, por el contrario, aquello que había logrado aprender y asimilar. Con tal procedimiento había que ser, para salir reprobado en el examen, o muy ignorante o de escasísima capacidad.

Al ingresar a la Universidad no pudimos seguir siendo su alumno ni menos cuando ya hombre de actividad independiente. Pero continuábamos sintiéndonos su discípulo. Por eso buscábamos su conversación o acudíamos a los sitios en que solía dar conferencias. Pero esto era muy poco frecuente. En cambio, podíamos escuchar su lección sin dificultades leyendo sus libros. Sabíamos que en ellos estaba el Maestro con toda su integridad moral e intelectual. 
Al igual que el alumno que toma notas en clase, nosotros acotamos en la lectura de los libros de don Enrique Molina la parte que más nos interesaba, ya porque coincidiéramos, ya porque no estuviéramos de acuerdo con ella. Como no siempre estábamos suficientemente preparados para seguirlo en la exposición de los problemas filosóficos, nuestras acotaciones no han pasado más allá de la impresión que siente un mero aficionado por las cosas superiores del espíritu. Son, pues, juicios impresionistas, de un lector profano y transeúnte, los marginados en las páginas de algunos libros suyos. Hemos querido, ahora, con motivo del homenaje que le rinde "Atenea", desenterrar de nuestro revuelto archivo esas apreciaciones, efímeras e inestables como las hojas de los diarios o revistas a que fueron destinadas.

De lo espiritual en la vida humana es, sin duda, la obra de mayor jerarquía de cuantas ha escrito don Enrique Molina. Enfoca en ella un problema filosófico, de singular trascendencia, al desentrañar el contenido esencial de la vida. Ahonda en las raíces del ser a fin de buscar un sentido a la existencia. Fluye del texto ese sentido como emanación sutil de un hálito de superioridad espiritual, que llega a nosotros como luz en medio de la confusión dentro de la cual actuamos. No pretende él darnos la orientación categórica que encierra en fórmula rígida el contenido vital de su filosofía. Aspira a que su libro sea "un compañero de viaje - un buen camarada - para los que deseen buscar en sus propias vidas un sentido trascendente". La vida tiene demasiados matices y facetas para encasillarla en un sistema filosófico que abarque todas sus infinitas perspectivas. Más que un sistema, propugna don Enrique Molina una actitud filosófica, la que debe estar presidida por el espíritu, que oscila entre lo inmediato y concreto, materializándose, y lo intangible e inmaterial, sublimándose. De la confluencia de estos dos aspectos que suele tomar el espíritu - anverso y reverso de una misma medalla - surge el verdadero sentido humano que ha de darse a nuestra existencia. Dominio de lo espiritual, orientado éticamente sobre lo transitorio material. Tal sería el contenido medular captado de la lectura de este libro. 
Con erudición, expone, analiza, critica las diversas tendencias filosóficas que han ido marcando surcos en el devenir de la humanidad. Ninguna doctrina fundamental ni sus correspondientes propugnadores escapan al fino escalpelo de sus observaciones exegéticas. La idea de progreso, por ejemplo, le induce a exponer las diferentes concepciones que de ella se ha tenido a través de su desarrollo histórico. Al referirse al materialismo histórico, refuta la difundida tesis de que los fenómenos económicos condicionan la vida de los pueblos. No niega que son muchos los países en que el florecimiento económico ha traído un gran desarrollo de las artes y de las ciencias. Pero ha habido hechos de gran significación en la evolución de la humanidad en que el factor material no ha contado para nada, hechos determinados, en ciertos casos, por sentimientos religiosos. Así, la lucha de los holandeses con los españoles, en los tiempos de Carlos V y Felipe II. Lo propio sucedió con los puritanos y cuáqueros, que abandonando las comodidades de su patria, fueron a buscar en los páramos y bosques vírgenes de la América del Norte una tierra donde practicar sus creencias y disfrutar de libertad espiritual. No podemos desconocer que la tónica de nuestra tiempo la da lo económico. "La interpretación económica de la historia - ha escrito Ortega y Gassetilumina bastante bien la realidad de nuestra época; pero, aplicada a otras, pronto advertimos su desdibujo". Don Enrique Molina, de acuerdo con el principio de que los valores del espíritu orientan la vida humana, rechaza el materialismo histórico y sólo acepta que "lo económico es un factor en el desarrollo de la civilización". Por nuestra parte, agregamos que es un factor fundamental, pues no se puede negar que la propia vida se asienta en lo biológico, es decir, en lo material. Expresa el señor Molina que "la inteligencia interviene en todos los momentos del proceso económico”. Màs para que esa inteligencia se mantenga y actúe normalmente, el organismo corporal debe conservarse en buenas condiciones de salud. Sin una alimentación adecuada, la inteligencia - vale decir espíritu- se resiente. Bien lo dijo don Quijote: "Sin el gobierno de las tripas no se puede llevar el peso de las armas". 
No siempre nos resulta fácil seguir el pensamiento filosófico de don Enrique Molina. No obstante, leemos su libro con sostenido incerés, pues adereza sus reflexiones con referencias a nuestra realidad actual e inmediata. De esta manera da vigencia a filosofías que expuestas escuetamente parecerían caducas por su inactualidad. El profesor se torna filósofo y al descender al plano de lo concreto e inmediato, se vuelve apóstol. De ello deriva que su libro es algo más que un camarada de viaje. Su palabra adquiere unción apostólica cuando señala rumbos, advierte peligros, otea horizontes.

Las fuerzas del espíritu animan las páginas de esta obra, sin que sea excluida ninguna de ellas: la religiosidad, el heroísmo, la moral, la cultura son los soportes en que ha de edificarse la personalidad humana. Por eso estimamos que la siguiente frase de don Enrique Molina precisa su pensamiento orientador: "Heraldo de lo espiritual, que puede ser oído, aun por los escépticos". Quien exalta con tal fervor la vida del espíritu no puede ser fanático, intransigente, unilateral; por ello su tolerancia enfrente de los problemas metafísicos y religiosos.

Su posición ante la vida es de elevada serenidad, de un equilibrio armonioso. Actitud apolínea la suya, que rechaza el sentido trágico, dionisíaco de la existencia. De ahí su escasa o ninguna admiración por Nietzsche, cuyas doctrinas refuta con fría y rigurosa lógica.

Escrito con sobria y sencilla elegancia, De lo espiritual en la vida humana es la más auténtica expresión del espíritu de don Enrique Molina, porque este libro es la síntesis de sus búsquedas y experiencias a través de la vida y de los libros.

Con el título Discursos universitarios ha reunido nuestro autor en un volumen cuatro discursos, tres de ellos con motivo del décimoquinto y vigésimo aniversarios del nacimiento de la Universidad de Concepción, y el cuarto referente al espíritu y funciones de la Universidad. Quien desee informarse acerca de los orígenes y desarrollo de esa institución de estudios superiores, tiene necesariamente que recurrir a esta fuente fidedigna que son los tres discursos aludidos. Por ellos sabemos de los tropiezos y vicisitudes que han debido 
superar los fundadores de la Universidad penquista hasta lograr la plenitud en que hoy se encuentra. Esfuerzo, perseverancia y optimismo fueron necesarios para salvar la incomprensión y escasez económica que se oponían a la realización de tan elevado propósito.

Cuenta don Enrique Molina, con palabras sencillas y cálidas, como fueron los primeros pasos de la Universidad. "El profesor de Química, señor Salvador Gálvez —dice-, no disponía de otros aparatos para hacer los experimentos de esa ciencia que tubos vacíos de Aspirina Bayer y un pequeño anafe, que él mismo debía llevar de su casa en el bolsillo". Así surgió la Universidad de Concepción, sin más instrumentos de acción que los quijotescos espíritus que le infundieron vida; y enfrente de ellos, el de don Enrique Molina, cruzado de la cultura.

Su desarrollo en lo material está atestiguado por los pabellones de clases, clínicas, laboratorios, bibliotecas, salas de conferencias, etc., y en lo espiritual, por la calidad de la enseñanza impartida por prestigiosos profesores extranjeros y chilenos. Su misión no se ha reducido sólo a otorgar títulos profesionales, sino también se ha orientado a la investigación científica y a estimular el cultivo de los valores literarios, científicos, filosóficos y artísticos.

En sus discursos don Enrique Molina, junto con historiar el origen de la Universidad y revelar sus progresos materiales y espirituales, lucubra en torno a problemas trascendentales que inquietan al hombre pensante. La hora en que vive la humanidad es demasiado trágica para que un temperamento superior como el suyo no sienta el drama que se representa en el mundo contemporáneo. Hechos salientes de este drama son las actuaciones de los regímenes totalitarios, que pretenden arrasar con dos mil años de cultura y con la herencia legítimamente recibida de la civilización grecorromana. Los llamados regímenes totalitarios (nacismo, fascismo y comunismo, confundidos hoy en una alianza bélica e invasora) (1) se fundamentan en la fuer-

(1) Estas observaciones fueron escritas en 1939, cuando la segunda guerra mundial estaba en pleno hervor sanguinario. 
za de las armas, ahogando toda efusión del espíritu. Enfrente de ellos, la democracia, con sus defectos y bondades, se alza como un refugio de la cultura. "Estos regímenes - dice el señor Molina-, muy idóneos tal vez para llevar a cabo movimientos de regeneración y reconstrucción nacional, merecen un juicio severo, porque en ellos se ha sacrificado también la libertad, no hay más opinión que la del gobierno y no se puede publicar nada contrario a la ideología de los que detentan el poder".

Como epifonema de cada uno de los discursos, reafirma su fe democrática y lanza admoniciones contra todos los sistemas de gobierno que restrinjan el libre desenvolvimiento del espíritu, porque para él la vida debe estar imantada de un noble ideal que le dé un sentido superior, más allá de las satisfacciones materiales.

En su discurso sobre "La crisis universitaria y las funciones de la Universidad" dilucida todo lo referente a las funciones de la Universidad, a la orientación de la cultura y a su relación con los problemas vitales de la humanidad. En las siguientes frases sintetiza su idea central en este orden de cosas: "A las universidades corresponde, en gran parte, salvar y saber conservar los valores éticos y jurídicos que la humanidad indudablemente posee, y estudiar las nuevas formas de vida que las necesidades de la época reclaman, de manera que, sin destruir lo bueno que tenemos, se pueda crear para los hombres un mundo mejor".

No obstante el motivo circunstancial que da origen a los discursos, su interés ha de prolongarse tanto por el valor documental como por las reflexiones del orador sobre sucesos y actos políticos que estremecieron patéticamente a la humanidad.

Cuando leímos Peregrinaje de un universitario nos pareció estar conversando con don Enrique Molina. Tan natural es su expresión, tan ágil corre su pluma, tan sin gravedad sus observaciones, que de pronto experimentamos la sensación de que el libro desaparecía de nuestras manos para escuchar la palabra amena, interesante, optimista del autor. Y ello se debe, seguramente, a que al escribirlo su actitud no fuera otra que la del viajero vigilante de todo lo que pasaba 
a su alrededor en el correr de las latitudes. No es la suya predisposición a coger sólo el paisaje desconocido, la cosa rara, el hecho exótico, sino la de captar todo cuanto cae bajo su mirada: lo plebeyo y lo digno, lo vulgar y lo noble, que todo tiene atractivo según el punto de vista en que se coloque el observador.

Don Enrique Molina, al recorrer tierras extranjeras, pudo decir como el romano: "puesto que soy hombre nada de lo humano me sea desconocido". No se asombra de nada, porque él ha alcanzado la serena actitud filosófica que dan la experiencia, el estudio y el suceder de los años. Su postura es natural, comprensiva, suavemente irónica en algunos casos, sin ningún gesto condenatorio ni de indignación siquiera. Mira, observa, anota. Hay hechos agradables y desagradables en su bitácora.

Los que estamos destinados a vivir sedentariamente, anclados a nuestras preocupaciones como un pontón que cabecea su aburrimiento, encontramos en este libro una evasión de la cotidiana jornada prosaica. Lo ha dicho él: "Viajar es huir un poco de lo cotidiano, de la monotonía de los días que se repiten". Sí, un poco, porque el alma jamás puede evadirse de nuestro propio ser. Donde vayamos ella está con nosotros y lo que vemos y observamos está teñido de nuestra personalidad. "El paisaje es un estado de alma", escribió Amiel. Don Enrique Molina logra liberarse, en cierta medida, de sí mismo, a fin de dar a sus observaciones objetividad.

La figura intelectual del rector de la Universidad de Concepción ha trasmontado las fronteras nacionales y alcanzado significación americana. Por tal motivo sus libros interesan vivamente en el extranjero y su palabra es requerida por universidades de diversos países. A ello se debe la invitación hecha por la Universidad de Cuyo (Mendoza), de donde siguió viaje a Córdoba y Buenos Aires. Por su libro sabemos de los agrados que él tuvo, de los triunfos de su palabra, y sabemos también de las molestias que sobrellevó, y sobre todo nos informa del vigor pujante del pueblo argentino en su anhelo por hacerse material y espiritualmente fuerte. Así, al lado de la observación objetiva está la reflexión fina, aguda, penetrante. Doble viaje el que 
nos proporciona este libro: a través de las tierras argentinas al describir el mundo físico que observó y a través del propio espíritu del autor.

Inserta don Enrique Molina el discurso dicho en la Universidad de Cuyo al iniciar ésta su labor escolar anual. Una vez más lo vemos enamorado de la democracia que considera el menos imperfecto de los regímenes políticos. Su posición ante el trágico momento internacional en que vive el mundo es clara y categórica. Ante los imperialismos que nos acechan como a presa codiciable, reafirma su fe en los destinos de este continente, que nació a la vida independiente unido desde su base por un mismo idioma, por iguales anhelos de porvenir y por idénticos peligros frente a enemigos comunes. "Los sudamericanos - dice- abrigamos en el alma la concepción de una unión de pueblos llevada a cabo, no por la fuerza, sino por la libre voluntad de naciones: La Confederación Iberoamericana".

Confesión filosófica tituló don Enrique Molina el discurso pronunciado con motivo de su incorporación como miembro académico de la Facultad de Filosofía y Educación de la Universidad de Chile. No se limitó a hilvanar las frases de cortesía usuales en estos casos, ni a una mera exposición retórica de temas manidos, tan frecuentes en las recepciones académicas. Se sobrepuso él a la situación, abdicó, podríamos decir, de toda actitud magisterial y docente, para darnos, desnuda su alma, la íntima confesión de su pensar y postura filosóficos frente a sí mismo y a la sociedad. No es fácil seguir su pensamiento, pues está tan nutrido de ideas abstractas que nos cuesta orientarnos en medio de estas disciplinas de suyo abstrusas. Felizmente, el señor Molina es claro en su exposición, de suerte que con buena voluntad se pueden desentrañar algunas de sus concepciones fundamentales.

Primeramente, se pregunta, ¿qué es lo esencial en filosofía? Y se responde diciendo que "lo esencial de la filosofía lo encontramos en las disciplinas que nos conducen a obtener una intuición del Ser, a tentar una interpretación suya y luego a definir nuestra actitud ante él". Este sería el pensamiento central de su confesión filosófica. Se 
remonta a un plano metafísico y reconoce que esta ansia eternamente insatisfecha del hombre de explicarse el principio de la vida, dio origen a todas las religiones. El no participa de ninguna, porque todo pensamiento religioso supone acatamiento dogmático y nada más lejos de su espíritu que la adhesión irreflexiva a ideas y doctrinas, aun cuando a veces la religiosidad entraña una actitud filosófica. Para adentrar en el campo especulativo es fundamental liberarse de todo prejuicio y el escepticismo es un buen camino para conseguirlo; pero como una disciplina purificada de la mente, para llegar a la comprensión y a la creencia en algo. En tal caso no es el escepticismo una actitud pasiva, de negación, como un reconocimiento de que la inteligencia es incapaz de obtener alguna verdad fundamental.

Mediante la ciencia se ha pretendido responder a los interrogantes del espíritu humano. El positivismo del siglo XIX creyó que la ciencia daría explicación a todos los fenómenos de la vida y del cosmos. Desgraciadamente, no ha sido así. Parece que la ciencia termina donde empieza la vida del espíritu, pues sólo explica aquello que es verificable. Por eso, con gran amplitud de criterio, don Enrique Molina reconoce "la necesidad de la metafísica y la imposibilidad de suprimirla se prueba con el hecho sencillo de que hay una región en que no cabe sino ella y de la cual no se puede prescindir". No es, pues, materialista su actitud filosófica; está más bien ella impregnada de un espiritualismo elevado, que nada tiene que hacer tampoco con las creencias religiosas.

Podría pensarse que una filosofía puramente especulativa sólo conduciría a obtener conocimientos vagos, muy distantes de la exactitud que es de rigor en la ciencia. Pero si aún no sabemos lo que es la vida, ya que de ella sólo conocemos sus manifestaciones, ¿cómo poder, entonces, reducirla a una fórmula precisa? 'Todas nuestras reacciones psíquicas - el dolor y la alegría, el amor y la desesperanzalas conocemos en la medida que se van exteriorizando impensadamente en nuestra intimidad recóndita. Misterioso mundo interior, tan misterioso como las resonancias que en lo profundo del alma suscita la armonía inefable de la música. Esta condición espiritual es lo que 
da jerarquía al hombre y lo releva de su calidad de animal. Por eso mismo también es respetable el sentimiento religioso en cuanto es una reflexión sobre la vida y el Ser, traducida en una conducta moral; pero siempre que este sentimiento no esté limitado por el fanatismo y la intolerancia.

Enfrente de la realidad cotidiana, don Enrique Molina se pregunta si la actitud del hombre debe ser optimista o pesimista. Ambas son inaceptables. Son extremos que oscilan entre la ingenuidad, que acepta buenamente cuanto se le ofrece, y el dogmatismo, que lo rechaza implacablemente, paralizando la voluntad de acción. Ante el bullir correntoso y febril de la vida, es recomendable la serenidad, el equilibrio, cuya expresión más perfecta se encuentra en la Grecia clásica, allí donde el hombre cultivó armoniosamente todos los aspectos de su personalidad. Bien comprendemos que esto no puede ser en la sociedad contemporánea más que una aspiración ideal, pues la excesiva especialización surgida como una consecuencia del maquinismo, impide que el hombre desarrolle en forma armónica sus facultades intelectuales y físicas.

Para alcanzar tal actitud de serenidad y equilibrio es necesario que el individuo conviva en una atmósfera de libertad, empezando por liberarse él mismo de los instintos, vicios y atavismos que lo encadenan y de toda suerte de tiranía que limite o anule su personalidad.

Nada más reconfortante en medio de las pasiones en que vive el hombre moderno, que aislarse del mundo material que le circunda y hacer, aun cuando no sea nada más que por higiene mental, un poco de vida contemplativa. Concentrarse en sí mismo y ayunar espiritualmente, para purificar su conciencia, es acaso lo más importante que puede realizar un hombre que presume de culto. Porque la vida humana es algo más que la realidad que nos aprisiona. Quizá la mayor justificación de nuestra existencia está en los goces del espíritu. Los que sólo viven urgidos por las angustias cotidianas, arrastran una existencia vulgar y mediocre, como sucede con los políticos 
que hacen ostentación de espíritu práctico y realista y cuya mayor satisfacción reside en el poder, los honores y las riquezas.

Apenas si hemos orillado algunos aspectos que enfoca don Enrique Molina en su interesante discurso académico, en que se plantean y sugieren problemas de profunda significación filosófica y humana, expresados con esa seducción que tienen siempre las cosas dichas con sinceridad, sencillez y hondura.

Formado en las normas de la serenidad clásica, seducido por la armonía y claridad de las culturas mediterráneas, convencido de las ventajas del racionalismo y del método discursivo, los libros y actitudes de don Enrique Molina están en consonancia con su formación espiritual, sin contorsiones y curvas súbitas que alteren el equilibrio de su mundo íntimo. Sólo esa curiosidad permanente y vigilante de su mente preclara, lo ha llevado a ahondar en la esencia del pensamiento agónico de Federico Nietzsche. Aún cuando existen entre el filósofo alemán y su exégeta antinomías irreconciliables, el autor de Nietzsche, dionisíaco y asceta se adelanta a decirnos que no ha olvidado "la simpatía comprensiva con que se deben abordar las cosas de la inteligencia".

No es tarea fácil seguir el dédalo intrincado y contradictorio y paradojal de Nietzsche. Existe una íntima correlación entre su vida y su ideario, lo que resta unidad y coherencia a sus conceptos. Pues su vida biológica parece haber condicionado, en buena parte, su filosofía, de suerte que un conocimiento pleno de ésta no se puede hacer desconociendo a aquélla.

Don Enrique Molina sigue paso a paso la trayectoria de la existencia y el pensamiento de Nietzsche, convencido de que ello es indispensable para la total comprensión de sus doctrinas. El retrato físico y psicológico del autor de Así habló Zaratustra puede servir para que un psiquiatra haga el diagnóstico de sus enfermedades y un psicoanalista determine la esencia de su personalidad. Nietzsche fue un enfermo toda su vida: padecía insomnios, constantes dolores de cabeza, males de la vista, perturbaciones intestinales y hepáticas, y terminó por perder la razón a consecuencia, según algunos de sus bió- 
grafos, de una sífilis. Todos ellos son antecedentes para explicarse sus reacciones y doctrinas; pero en ningún caso para descalificarlas, como lo hacen quienes no pueden acomodar su visión personal a las perspectivas alucinantes del pensamiento nietzscheano.

Ya en su primera obra, El origen de la tragedia, aparecen expuestas las doctrinas que han de informar su filosofía. Según Nietzsche, los griegos no fueron únicamente el pueblo del arte sereno, apolíneo, de la armonía y el racionalismo socrático. Tuvieron ellos también, al crear la tragedia inspirada en los antiguos mitos, un sentido exaltado y violento de la vida, sombrío y embriagador, danzando en conjunto la muerte y el placer y estimulando los instintos en el culto a Dionisios. En el pensamiento contradictorio y oscilante del filósofo alemán, advertimos como una constante el sentido dionisíaco que reclama para la existencia del hombre.

En verdad, hay en Nietzsche un cuerpo de doctrinas, que si bien no fueron expuestas en forma sistemática y razonada, le dan categoría de auténtico filósofo, que don Enrique Molina le niega al considerarlo sólo como un pensador. Sus ideas esenciales aparecen en su obra fundamental Así habló Zaratustra, expuestas a base de símbolos, expresados en estilo vehemente y radiante.

Se ha dicho que sus doctrinas han servido de basamento al nacismo. Sin duda existen entre ambas puntos coincidentes. Nietzsche execraba el cristianismo y la democracia, glorificaba lo que él llamaba "el superhombre", el hombre fuerte instintivamente. Pero a su vez abominaba de la multitud, del pensamiento gregario, de la vulgaridad, de la ramplonería. Reclamaba para Alemania un nuevo tipo humano, que encarnara los nuevos valores, reaccionando contra la decadencia traída por el cristianismo, el cual, con su actitud de piedad para con el débil ha favorecido la influencia del "tipo enfermizo, raquítico y miserable del europeo de hoy".

Según don Enrique Molina, Nietzsche es ante todo un libelista, que habla en forma de aforismos sin preocuparse de convencer, pues sus afirmaciones son categóricas. Parece un iluminado que se dejara llevar por el fuego de las palabras, embriagado por su colorido y 
cadencia. De ahí que Nietzsche es sobre todo un poeta y un artista del estilo.

Don Enrique Molina desentraña y pone en evidencia las contradicciones y falsedades de los pensamientos nietzscheanos. Habría sido interesante también que nos hubiera dicho cuántos de ellos están vigentes y cómo Nietzsche resultó ser un profeta del momento agónico en que vive la humanidad.

En uno de sus últimos libros, Tragedia y realización del espíritu, don Enrique Molina nos ha dado una demostración de su extraordinaria vitalidad intelectual. Parece que para él el tiempo no pasara con su carga de quebrantos físicos y morales, como anuncio inexorable de que la vida tiene su término fatal y de que nuestro cuerpo y espíritu sólo logran un fugaz estado de plenitud. Basta leer los ensayos que forman esta obra para darse cuenta de que su voluntad está tensa y recia y de que su espíritu no sólo se muestra ágil, sino también con ese optimismo de quien disfruta de los goces superiores de la vida, integralmente. El desengaño, la decepción, el pesimismo, la angustia, la desesperanza, la amargura, que de modo sutil e implacable van resquebrajando la contextura anímica aun del más fuerte, no han rozado siquiera la enteriza personalidad del maestro penquista.

No sólo ha sido él un explorador sagaz de los ámbitos filosóficos, en una rebusca pertinaz para extraer las esencias que han inquietado a antiguos y modernos. Ha conformado su propia conducta a esos principios morales y espirituales, considerados fundamentales del ser que aspira a una vida socialmente eficaz. Así, ha aunado la contemplación introspectiva, el mirarse a sí mismo en un proceso de autoanálisis, con la acción realizadora al dar al mundo circundante su experiencia y saber en hechos que materializan su propia vida interior.

"El' espíritu - dice- tiene que sacar de sí mismo las fuerzas para sobreponerse a su angustia y ésas las encuentra en sus virtudes y en dos realizaciones supremas. Estas no son otras que el amor desinteresado y el valor. Comprendemos que insinuamos por esto último recursos difíciles porque lindan con la santidad y el heroísmo. Recla- 
man del alma su tensión máxima. El amor desinteresado lleva en sí la ventaja de no dejar, desde luego, lugar para la desilusión y el desengaño y cabe afirmar de él también lo que he dicho de la música en mi Confesión filosófica: "que nos transporta al centro de una de las formas del misterio y así vierte sobre nuestro espíritu su virtud de apaciguamiento y su don de goces superiores. El misterio dejó de inquietarnos por instantes porque pasamos a sentirnos en medio de él. Nuestro afán de conocer se transforma y satisface en un gozoso acto de vivir".

De las líneas precedentes se deduce que su conducta moral y social y su gozosa vitalidad son la resultante de sus reflexiones filosóficas sobre el Ser y la Vida.

Sus meditaciones sobre el sentido de la muerte y de la vida reafirman su concepción optimista, rechazando al mismo tiempo el conformismo negativo y la resignación abúlica frente a la realidad ineluctable de la caducidad de las cosas humanas. No se aventura, tampoco, en juicios categóricos - afirmativos o negativos- ante el misterio que significa la desintegración material del Ser. Prefiere él ahondar en los problemas inextricables que ofrece la vida, lo cierto y tangible, antes de ambular por las tinieblas de lo que se ha dado en llamar "el más allá". "No cabe, por desgracia - dice-, afirmar nada con certidumbre sobre el más allá; pero, ¡cuidado!, que por la misma razón tampoco cabe negar nada. El desolado credo del existencialismo, de que el hombre sea un ser para la muerte y nada más, se halla tan fuera de prueba como la gloria eterna. Esto nos aconseja una actitud abierta y modesta ante el misterio, actitud que nos dará amplitud de espíritu y que no está reñida ni con las investigaciones de nuestra inteligencia ni con afanes de progreso. Con lo que nos encontramos en plena indagación sobre el sentido de la vida".

Con gran claridad expositiva nos da don Enrique Molina una amplia y penetrante visión de la vida y obra de Descartes. No se limita a una mera exposición de la filosofía cartesiana. Hace una interpretación de ella a la luz de conceptos filosóficos actuales. Así, analiza la opinión que de Descartes ha merecido al conocido filósofo ca- 
tólico contemporáneo Maritain, quien acusa a Descartes de "haber hecho de la explicación mecanicista el único tipo concebible de explicación científica; de haber reivindicado para nuestra inteligencia la autonomía perfecta, la independencia absoluta, reemplazando el arte creador y la obra de Dios por el mundo imbécil del racionalismo, principio secreto de la disolución de nuestra cultura y del mal que aqueja al Occidente apóstata". Concluye Maritain diciendo: "Así como la reforma luterana es el gran pecado alemán, la reforma cartesiana es en la historia del pensamiento moderno el gran pecado francés. El cartesianismo representa no tanto lo que es la vida y mensura en nosotros, sino más bien lo que es exceso y franqueza". Don Enrique Molina estima increíbles estos apasionados juicios del filósofo del socialcristianismo, pues Descartes proclamó reiteradamente su fe religiosa y su creencia en el Dios de los católicos.

Como siempre, don Enrique Molina adopta una postura ecléctica, de equilibrio, de justo medio. Sus juicios parecen expurgados de todo subjetivismo arbitrario y de enfáticas afirmaciones. Prefiere desmenuzar, bucear en las profundidades del pensamiento, extraer esencias conceptuales y exhibir cuanto ha recogido en sus redadas filosóficas. Y ello tiene su corroboración más amplia en el ensayo "La sabiduría de los griegos", con que finaliza el libro comentado.

No podríamos decir con propiedad que vuelve don Enrique Molina, en este ensayo, a profundizar en el alma helénica, pues creemos que él siempre ha vivido inmerso en ella, hasta llegar a identificar su propia vida con la práctica de algunas de las virtudes más distintivas de la filosofía griega como es la sofrosine: prudencia, moderación, sobriedad, dominio de sí mismo. Al evocar las figuras señeras del pensamiento clásico, expresa don Enrique que no son sólo "sombras venerables". Son, para él, "espíritus amigos que viven al lado de nosotros, que viven para nosotros y que, cuando queremos escucharlos, saben hablarnos con sus palabras y con su ejemplo de las buenas cosas eternas de la vida. En nosotros está hacer nuestra jornada por el mundo en tan bien inspirada y delectable compañía”. 
Bien decíamos que no se había separado jamás de esas compañías, que su espíritu ha vivido en ese mundo superior patente en el arte, la literatura y la filosofía griegas. Mientras el pensamiento contemporáneo rebulle en medio de contradicciones y absurdos, angustiado por trágicos avatares, tratando de interpretar las circunstancias en torno, don Enrique Molina rinde culto a Apolo, símbolo de serenidad, de equilibrio, de armonía. Los tormentos dionisíacos, las torturas barrocas, el agonismo existencialista, no alteran la claridad y sencillez de sus concepciones, como trasunto de su condición anímica forjada dentro de los moldes clásicos imperecederos.

Hemos hecho una rápida incursión a través de algunos libros de don Enrique Molina. De nuevo nos consideramos su discípulo, atento a su lección. Como hace más de cuarenta años, ese alumno de antaño ha revivido momentos de ilusionada esperanza, y en el descenso fatal de los años, siente reverdecida su alma con los brotes de una primavera cuajada de optimismo. Milagro provocado por las palabras y el ejemplo del Maestro. 